Article

\title{
Aflatoxin Reduction and Retardation of Aflatoxin Production by Microorganisms in Doenjang during a One-Year Fermentation
}

\author{
Vishal Kumar ${ }^{1,+}$, Ashutosh Bahuguna ${ }^{1,+}$, Srinivasan Ramalingam ${ }^{1}$, Jong Suk Lee ${ }^{2}$, Sung Soo Han ${ }^{3,4}$, Hyang \\ Sook Chun ${ }^{5}$ and Myunghee Kim ${ }^{1,4, *}$
}

check for

updates

Citation: Kumar, V.; Bahuguna, A.; Ramalingam, S.; Lee, J.S.; Han, S.S.; Chun, H.S.; Kim, M. Aflatoxin Reduction and Retardation of Aflatoxin Production by Microorganisms in Doenjang during a One-Year Fermentation. J. Fungi 2022, 8, 190. https://doi.org/10.3390/ jof8020190

Academic Editors: Zhi-Yuan Chen and Pooja Bhatnagar-Mathur

Received: 14 December 2021 Accepted: 11 February 2022 Published: 15 February 2022

Publisher's Note: MDPI stays neutral with regard to jurisdictional claims in published maps and institutional affiliations.

Copyright: (C) 2022 by the authors. Licensee MDPI, Basel, Switzerland. This article is an open access article distributed under the terms and conditions of the Creative Commons Attribution (CC BY) license (https:// creativecommons.org/licenses/by/ $4.0 /)$.
1 Department of Food Science and Technology, Yeungnam University, Gyeongsan 38541, Gyeongsangbuk-do, Korea; vkaggarwal180@gmail.com (V.K.); ashubahuguna@gmail.com (A.B.); sribt27@gmail.com (S.R.)

2 Division of Food \& Nutrition and Cook, Taegu Science University, Daegu 41453, Gyeongsangbuk-do, Korea; jslee1213@ynu.ac.kr

3 School of Chemical Engineering, Yeungnam University, Gyeongsan 38541, Gyeongsangbuk-do, Korea; sshan@yu.ac.kr

4 Institute of Cell Culture, Yeungnam University, Gyeongsan 38541, Gyeongsangbuk-do, Korea

5 School of Food Science and Technology, Chung-Ang University, Anseong 17546, Gyeonggi-do, Korea; hschun@cau.ac.kr

* Correspondence: foodtech@ynu.ac.kr; Tel.: +82-53-810-2958

$+\quad$ These authors contributed equally to this work.

\begin{abstract}
Meju, a raw material for doenjang preparation, is highly vulnerable to aflatoxin-producing fungi. The aim of this study was to evaluate the effect of a one-year fermentation on aflatoxins and aflatoxin-producing fungi in doenjang spiked with aflatoxins B1, G1, B2, and G2 and inoculated with toxigenic Aspergillus flavus. A significant reduction in aflatoxins was observed after a year of fermentation, measuring $92.58 \%, 100 \%, 98.69 \%$, and $100 \%$ of B1, G1, B2, and G2, respectively. After a year of fermentation, $6.95 \pm 3.64 \mu \mathrm{g} / \mathrm{kg}$ of total aflatoxin was detected, which represents a $97.88 \%$ reduction in the total aflatoxin compared with the initial value $(328.83 \pm 36.60 \mu \mathrm{g} / \mathrm{kg})$. Several aflatoxindegrading fungi (Aspergillus versicolor, Cladosporium subcinereum, Aspergillus ochraceus) and bacteria (Bacillus albus, Bacillus velezensis) isolated from doenjang were identified as the major contributors to the reduction of aflatoxin. Furthermore, it was observed that most of the aflatoxin contamination in doenjang occurred during the meju stage, and this stage was found to be most susceptible to $A$. flavus contamination and growth. These findings reveal that native microorganisms mediate aflatoxin clean-up in doenjang during fermentation and support the use of such microorganisms as a starter culture for the preparation of aflatoxin-free doenjang.
\end{abstract}

Keywords: doenjang; fermentation; aflatoxin; Aspergillus flavus; degradation; fungi; bacteria

\section{Introduction}

Soybean-based fermented foods are an integral part of the diet in many Southeast Asian countries, including Korea, China, and Japan [1-3]. Examples of soybean-based fermented foods include thua nao from Thailand, sufu from China, natto from Japan, tempeh from Indonesia, and doenjang from Korea. Doenjang is a traditional fermented soybean paste prepared using mеju as a starter culture. Doenjang quality is influenced by its raw ingredients and the fermenting microbial communities [4,5]. Doenjang is made of meju and salt and is naturally fermented by diverse microbial communities. Both aerobic and anaerobic fermentation take place during doenjang-meju preparation. In the exterior part of doenjang-meju, aerobic fermentation takes place, whereas in the interior part, anaerobic or microaerophilic fermentation is predominant. Microbial communities also vary greatly in the interior and exterior parts of doenjang-meju fermentation. The outer part is rich in aerobic microorganisms such as Bacillus, whereas the internal part is abundant in anaerobic, 
microaerobic, and facultative anaerobic bacteria such as Enterococcus, Lactobacillus, Clostridium, and Myroides [6]. Occasionally, meju can be contaminated with aflatoxin-producing fungi such as Aspergillus flavus and Aspergillus parasiticus, leading to the contamination of doenjang with aflatoxins [7]. Aspergillus flavus produces aflatoxins B1 and B2, whereas $A$. parasiticus produces aflatoxins G1 and G2 [8,9]. Aflatoxin contamination poses a serious challenge to food safety, as it is associated with several health hazards. Aflatoxin B1 exerts strong mutagenicity and carcinogenicity; it is classified as a Group 1 human carcinogen by the International Agency for Research on Cancer [10,11]. The Korea Food and Drug Administration limits total aflatoxin and aflatoxin B1 levels in doenjang to $15 \mu \mathrm{g} / \mathrm{kg}$ and $10 \mu \mathrm{g} / \mathrm{kg}$, respectively, to ensure safe consumption.

Doenjang is commonly consumed in Korea and is prepared either commercially or traditionally at home. Homemade doenjang is often prepared using traditional fermentation methods involving natural microflora. However, commercial doenjang is prepared in a controlled environment using selected microbial strains under strict fermentation conditions [12]. Thus, homemade doenjang is more vulnerable to contamination by undesired microorganisms. Therefore, it is necessary to understand the changes in aflatoxin levels that occur during the fermentation of traditional doenjang to ensure the safety of doenjang consumption. This study was conducted to examine aflatoxin levels in doenjang prepared by fermentation over a year. Furthermore, doenjang was artificially contaminated with aflatoxins and inoculated with aflatoxin-producing fungi (A. flavus) to examine the effect of fermentation on aflatoxin levels, fungal growth, and aflatoxin production. Additionally, different microorganisms (bacteria and fungi) were isolated from doenjang and examined for their aflatoxin degradation ability to develop an effective starter culture for the preparation of aflatoxin-free doenjang.

\section{Materials and Methods}

\subsection{Materials}

Salt and soybean used for doenjang preparation were purchased from a local market (Gyeongsan, Gyeongsangbuk-do, Korea). Immunoaffinity columns for aflatoxin purification were supplied by VICAM (Milford, MA, USA). Acetonitrile and methanol for high-performance liquid chromatography (HPLC) were supplied by Sigma-Aldrich (St. Louis, MO, USA). Whatman filters $(0.22 \mu \mathrm{m})$ were used to filter HPLC solvents. The standard aflatoxins B1, G1, B2, and G2 were purchased from LIBIOS (Vindry-sur-Turdine, France). The aflatoxin-producing strain A. flavus KACC45470 was procured from the Korean Agricultural Culture Collection (KACC, Suwon, Korea). Dulbecco's Modified Eagle's Medium (DMEM) and fetal bovine serum (FBS) were procured from Gibco (Waltham, MA, USA). 3-(4,5-Dimethylthiazol-2-yl)-2,5-diphenyltetrazolium bromide (MTT) and antibiotics were purchased from Invitrogen (Waltham, MA, USA). Dimethyl sulfoxide (DMSO) was purchased from Sigma-Aldrich (St. Louis, MO, USA). Human skin fibroblast cells were procured from the American Type Culture Collection (ATCC, Manassas, VA, USA).

\subsection{Preparation of Doenjang}

Meju was prepared as depicted in Figure 1. Soybeans were soaked in water for $12 \mathrm{~h}$ and then steamed at $100-105^{\circ} \mathrm{C}$ for $3 \mathrm{~h}$. The steamed soybeans were cooled at room temperature $\left(25.0 \pm 2.5^{\circ} \mathrm{C}\right)$, mixed with an Aspergillus oryzae culture, and incubated for 4 days at $30^{\circ} \mathrm{C}$, followed by drying. The prepared meju was mixed with three-fold of $20 \%$ salt solution and fermented at room temperature for 2 months. After primary fermentation, the liquid part (soy sauce) was separated, and the solid soybean paste (doenjang) was further fermented for 12 months at room temperature, during which samples were collected for aflatoxin analysis.

\subsection{Artificial Contamination of Doenjang}

To evaluate the effect of the doenjang matrix on aflatoxin reduction, artificial contamination experiments were carried out as follows. 


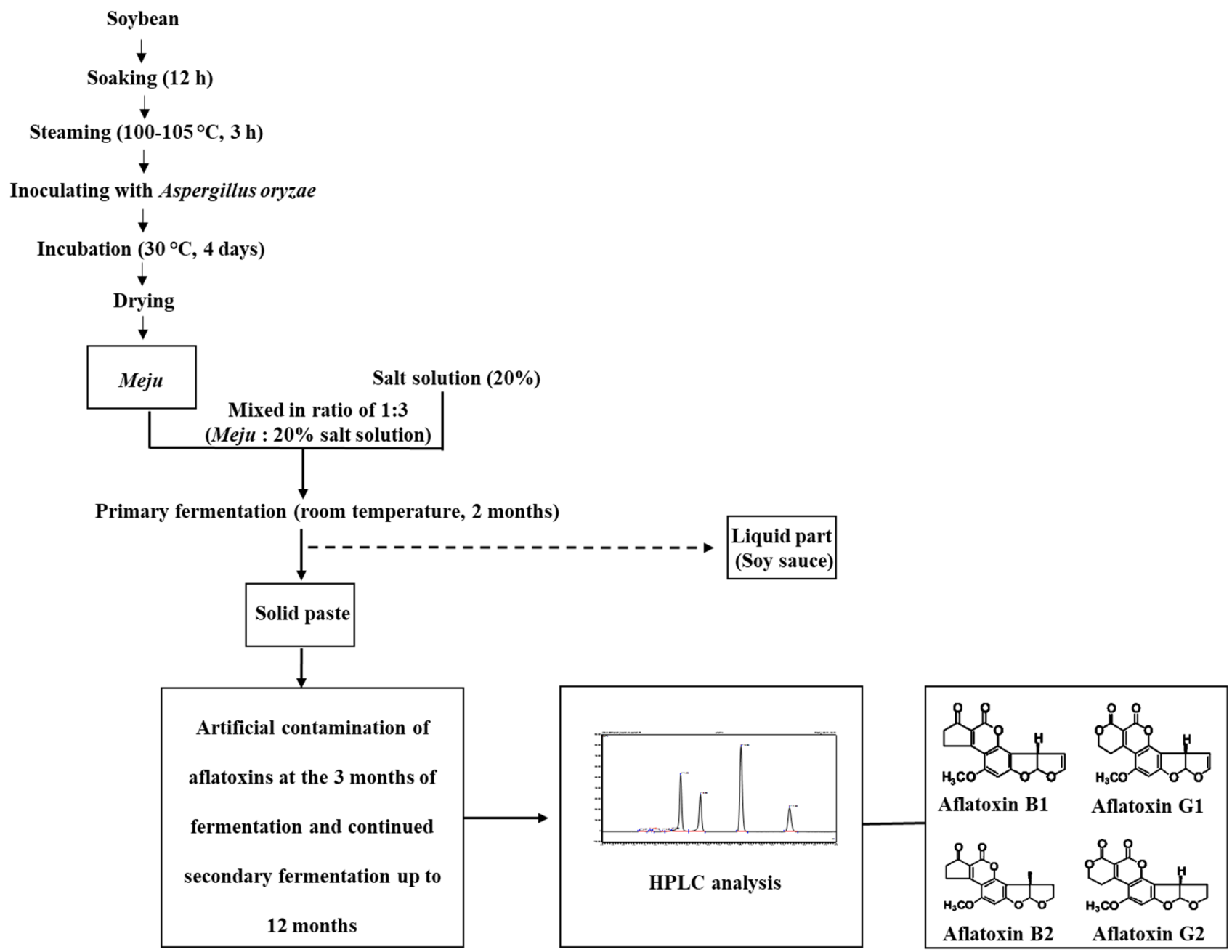

Figure 1. Flow diagram representing the experimental design for doenjang preparation, aflatoxin spiking, and aflatoxin analysis in doenjang.

\subsubsection{Artificial Contamination of Commercial Aflatoxins}

Doenjang was artificially contaminated with aflatoxins B1, G1, B2, and G2. Each aflatoxin was prepared at a concentration of $60 \mu \mathrm{g} / \mathrm{mL} ; 500 \mu \mathrm{L}$ of the aflatoxin mixture was added to $300 \mathrm{~g}$ of doenjang samples to obtain a final concentration of $100 \mu \mathrm{g} / \mathrm{kg}$ for each aflatoxin. After mixing, all samples were incubated at room temperature for 12 months. Experiments were carried out in three independent experiments, each containing $300 \mathrm{~g}$ of doenjang spiked with $100 \mu \mathrm{g} / \mathrm{kg}$ of each aflatoxin. Before the sample collection, aflatoxinspiked doenjang was mixed thoroughly, and $15 \mathrm{~g}$ of the sample was collected from each of the triplicates. The remaining samples were kept for further fermentation and collection of the samples at different fermentation times. Additionally, a control containing aflatoxin-spiked doenjang was maintained at $4{ }^{\circ} \mathrm{C}$ to stop the activity of microorganisms and fermentation. Furthermore, doenjang was autoclaved to eradicate the native microorganisms and then spiked with aflatoxins. The aflatoxin-spiked autoclaved doenjang was stored at room temperature and served as the control. Aflatoxin levels in the control samples were analyzed after 12 months.

\subsubsection{Artificial Contamination of A. flavus}

A toxigenic strain of $A$. flavus was grown at $28^{\circ} \mathrm{C}$ for seven days in potato dextrose broth (PDB) in a shaking incubator (150 rpm) to obtain the mycelial biomass. The mycelial biomass was separated through filtration using a double-layered muslin cloth and washed twice with double-distilled water. Finally, mycelial biomass ( $7.5 \mathrm{~g}$ ) was added to $300 \mathrm{~g}$ 
of doenjang samples. The experiments were performed in three independent experiments. Before the sample collection, A. flavus-inoculated doenjang was mixed thoroughly, and $15 \mathrm{~g}$ of the sample was collected from each of the triplicates. The remaining samples were kept for further fermentation and collection at different fermentation times.

\subsection{Aflatoxin Extraction and HPLC Analysis}

Doenjang samples (10 g) were homogenized for $2 \mathrm{~min}$ at 10,000 rpm in $50 \mathrm{~mL}$ of $80 \%$ methanol. This was followed by the addition of $25 \mathrm{~mL}$ hexane and $30 \mathrm{~min}$ of shaking at room temperature. The sample was filtered through Whatman filter paper (No. 4), and the filtrate was further diluted by eight-fold using triple-distilled water containing $0.1 \%$ Tween 20. The diluted filtrate was passed through a glass fiber filter $(1.6 \mu \mathrm{m})$ to obtain a clear solution. Then, $20 \mathrm{~mL}$ of the filtered solution was passed through the VICAM AflaTest affinity column to bind the aflatoxins. The affinity column was then washed with $10 \mathrm{~mL}$ of distilled water to remove impurities and salts. After $30 \mathrm{~min}$, the aflatoxins were eluted using $4 \mathrm{~mL}$ of methanol containing $0.1 \%$ acetic acid. The eluents were dried using $\mathrm{N}_{2}$ gas, reconstituted in $600 \mu \mathrm{L}$ of $20 \%$ acetonitrile:trifluoroacetic acid (4:1) solution, and filtered using a $0.2 \mu \mathrm{m}$ syringe filter. Aflatoxins were quantified using an UltiMate 3000 HPLC system (Thermo Fisher Scientific, Waltham, MA, USA). A Cloversil-C18 column (4.6 mm width $\times 250 \mathrm{~mm}$ length; pore size $5 \mu \mathrm{m}$; Shiseido Co., Ltd., Tokyo, Japan) was used for separation at a column temperature of $30^{\circ} \mathrm{C}$. The injection volume was $20 \mu \mathrm{L}$, and the mobile phase comprised water:acetonitrile:methanol (3:1:1, $v / v)$. The flow rate was maintained at $0.8 \mathrm{~mL} / \mathrm{min}$. The excitation and emission wavelengths of the spectra were $360 \mathrm{~nm}$ and $450 \mathrm{~nm}$, respectively. For the quantification of aflatoxin in doenjnag samples, a calibration curve was prepared using the standard aflatoxins B1, G1, B2, and G2 (Figure S1 and Table S1).

\subsection{Aflatoxin Production by A. flavus at Different Stages of Doenjang Preparation}

A. flavus spores were inoculated at three different stages of doenjang preparation: meju formation and primary and secondary fermentation stages (Figure 1). For meju preparation, $\sim 10^{6}$ spores of A. flavus were inoculated in $200 \mathrm{~g}$ of boiled and crushed soybeans. Meju bricks were prepared and stored at room temperature. Then, meju was examined for aflatoxin production at different time points (0 day, 10 days, 20 days, and 40 days). For the A. flavus inoculation at the primary fermentation stage, $200 \mathrm{~g}$ of commercial meju was inoculated with the spores of $A$. flavus $\left(\sim 10^{6}\right)$, and finally, the meju was dipped in the $20 \%$ salt solution and stored at room temperature. This meju was analyzed for aflatoxin production at 0 day, 15 days, 30 days, 45 days, and 60 days of fermentation. For the secondary fermentation, 60 days-aged primary fermented meju $(200 \mathrm{~g})$ was inoculated with A. flavus $\left(\sim 10^{6}\right)$ and incubated at room temperature for 6 months. Fermented samples were collected and processed for aflatoxin quantification after 1 month, 2 months, 3 months, 4 months, 5 months, and 6 months.

\subsection{Aflatoxin Degradation by Microflora from Doenjang}

The native microorganisms present in doenjang were extracted by suspending $1 \mathrm{~g}$ of doenjang sample in $9 \mathrm{~mL}$ of $0.85 \%$ saline. After $2 \mathrm{~h}$ of shaking, $0.5 \%(v / v)$ of the extracted suspension was inoculated in nutrient broth spiked with $100 \mathrm{ng} / \mathrm{mL}$ each of aflatoxins B1, G1, B2, and G2. After $5 \mathrm{~d}$ of incubation at $30{ }^{\circ} \mathrm{C}$, the culture supernatant and pellet fractions were collected individually by centrifugation at 10,000 rpm for $10 \mathrm{~min}$. Both fractions were analyzed separately to detect the residual aflatoxins. Doenjang samples showing aflatoxin degradation were further processed for the isolation of microorganisms (bacteria and fungi) using the serial dilution method. Briefly, $1 \mathrm{~g}$ of doenjang was mixed with $9 \mathrm{~mL}$ of $0.85 \%$ saline and serially diluted to a $10^{-7}$ dilution. Samples from each dilution were spread on nutrient agar plates and incubated at $30^{\circ} \mathrm{C}$ for $48 \mathrm{~h}$ to allow the growth of bacteria. Similarly, samples from each dilution were spread onto a potato dextrose agar plate containing kanamycin $(50 \mu \mathrm{g} / \mathrm{mL})$ and incubated at $28{ }^{\circ} \mathrm{C}$ for 7 days to allow the 
growth of fungi. Different bacterial and fungal strains were isolated by repetitive streaking to obtain a pure culture.

All bacterial isolates were cultured for $48 \mathrm{~h}$ in nutrient broth at $30{ }^{\circ} \mathrm{C}$ in a shaking incubator at $150 \mathrm{rpm}$. Cell-free supernatant (CFS) was collected by centrifuging the culture broth at 10,000 rpm for $10 \mathrm{~min}$. The CFS of bacterial isolates was then spiked with the aflatoxin mixture (B1, G1, B2, and G2 at a concentration of $1000 \mathrm{ng} / \mathrm{mL}$ each) and incubated for 7 days at $35{ }^{\circ} \mathrm{C}$. After seven days of incubation, aflatoxins were extracted from the aflatoxin-mixture-spiked CFS and analyzed using HPLC, as described in Section 2.4.

All fungal isolates were cultured for 15 days in potato dextrose broth at $28{ }^{\circ} \mathrm{C}$ in a shaking incubator at $150 \mathrm{rpm}$. CFS was collected by centrifuging the culture broth at $10,000 \mathrm{rpm}$ for $10 \mathrm{~min}$. The CFS of fungal isolates was then spiked with the aflatoxin mixture (B1, G1, B2, and G2 at a concentration of $1000 \mathrm{ng} / \mathrm{mL}$ each) and incubated for 7 days at $35^{\circ} \mathrm{C}$. After seven days of incubation, aflatoxins were extracted from the aflatoxinmixture-spiked CFS and analyzed using HPLC, as described in Section 2.4.

\subsection{Detection of Aflatoxin Production by Fungi Isolated from Doenjang}

All the fungal isolates from doenjang were analyzed for the aflatoxin (B1, G1, B2, G2) production by inoculating the mycelium directly into $50 \mathrm{~mL}$ PDB, followed by $7 \mathrm{~d}$ of incubation at $28^{\circ} \mathrm{C}$ in a rotatory shaker $(150 \mathrm{rpm})$. Finally, the content was quantified for the production of aflatoxins (B1, G1, B2, G2) by using HPLC, as per the method adopted in Section 2.4.

\subsection{Effect of Salt Concentration on Aflatoxin-Producing Fungi}

The aflatoxin-producing fungal isolates from doenjang and standard aflatoxin-producing strains of $A$. flavus were tested for their salt tolerance capabilities. The fungal spores of the respective isolates were inoculated in PDB containing different salt concentrations $(12 \%, 14 \%, 16 \%, 18 \%$, and $20 \%)$. After 15 days incubation at $28{ }^{\circ} \mathrm{C}$, growth and mycotoxin production were analyzed at each salt concentration.

\subsection{Molecular Identification of Microorganisms Isolated from Doenjang}

Bacteria and fungi isolated from doenjang were identified via 16S rRNA gene and internal transcribed spacer sequencing, respectively, at the SolGent (Daejeon, Korea) commercial sequence facility. The amplified $16 \mathrm{~S}$ rRNA genes and internal transcribed spacer sequences of the isolated bacteria and fungi, respectively, were searched for similarities in the NCBI GenBank database using the nBLAST tool. Sequences showing high similarity with the query sequences were aligned in CLUSTALW using the Mega6.0 software [13] and processed for phylogenetic analysis using the neighbor-joining method.

\subsection{Toxicity Analysis of Aflatoxin and Aflatoxin Degradation Products in Doenjang}

The toxicity of the aflatoxin and aflatoxin degradation products in doenjang was determined by examining human skin fibroblast cell viability.

\subsubsection{Cells and Cell Culture}

Human skin fibroblast cells were maintained in DMEM containing 10\% $(v / v)$ FBS and a cocktail of penicillin and streptomycin. The cells were maintained at $37^{\circ} \mathrm{C}$ in the presence of $5 \% \mathrm{CO}_{2}$.

\subsubsection{Extraction of Aflatoxin and Its Degradation Products form Doenjang}

Five grams of doenjang (samples were collected at zero days and twelve months fermented) was homogenized with ten milliliters of distilled water, followed by mixing with twenty milliliters of hexane. The doenjang suspension was shaken at $120 \mathrm{rpm}$ in a shaking incubator. After $30 \mathrm{~min}$, the hexane phase was removed, and the aqueous suspension was mixed with $15 \mathrm{~mL}$ of chloroform to extract the aflatoxin and aflatoxin 
degradation products. Finally, chloroform was evaporated at $50{ }^{\circ} \mathrm{C}$ under a gentle stream of $\mathrm{N}_{2}$ gas, and the dried samples were dissolved in $100 \mu \mathrm{L}$ of DMSO.

\subsubsection{Toxicity Determination using Human Skin Fibroblast Cell Viability}

The toxicity of the aflatoxin and aflatoxin degradation products extracted from doenjang was examined by the MTT assay [14]. Briefly, human skin fibroblast cells $\left(1 \times 10^{4}\right.$ cells $\left./ \mathrm{mL}\right)$ were seeded in a 96-well culture plate and incubated for $24 \mathrm{~h}$ at $37^{\circ} \mathrm{C}$ in a $\mathrm{CO}_{2}$ incubator. The cells were subsequently treated with $15 \mu \mathrm{L}$ of samples extracted from doenjang on Day 0 and 12 months fermented products. After $24 \mathrm{~h}$ of incubation, cells were mixed with $10 \mu \mathrm{L}$ of MTT solution $(5 \mathrm{mg} / \mathrm{mL})$ for $4 \mathrm{~h}$. As a result, the formazan crystals formed and were dissolved in DMSO, and the cell viability was determined by measuring the absorbance at $540 \mathrm{~nm}$. The results are represented as the percentage of viable cells. Human skin fibroblast cells without any treatment were used as the control, and their cell viability was considered $100 \%$.

\subsection{Statistical Analyses}

All experiments were performed in triplicate, and the results are presented as the mean \pm standard deviation. The SPSS-16 software (IBM, Chicago, IL, USA) was used to evaluate the statistical significance between groups, employing ANOVA and the Duncan test for post hoc analysis at $p<0.05$.

\section{Results and Discussion}

\subsection{Aflatoxin Analysis in Non-Contaminated Doenjang during Fermentation}

Fermented foods such as doenjang are vulnerable to mycotoxin contamination because of the long duration of fermentation in the natural environment [15]. Mycotoxins, such as aflatoxins, are the most serious toxicants in fermented foods because of their potential toxicity to humans and animals $[9,16,17]$. Several studies have reported the presence of aflatoxins in different doenjang samples $[15,18]$. Therefore, it is imperative to examine the presence of such toxins to determine the safety of fermented food consumption. In the present study, we examined the presence of aflatoxins B1, G1, B2, and G2 in doenjang samples during 12 months of fermentation. The doenjang preparation was almost free from aflatoxin contamination. However, a non-considerable (below the limit of quantification) (Table S1) amount of aflatoxins was traced in a few samples (Table S2), which spontaneously disappeared with the fermentation time. The disappearance of aflatoxins during the fermentation could be due to the presence of different microorganisms that have the potential to degrade aflatoxins, or they could be antagonistic towards mycotoxin-producing fungi. In addition, several physical and chemical factors that arise during fermentation may have contributed to the effective reduction of aflatoxins $[19,20]$.

\subsection{Aflatoxin Analysis in Artificially Contaminated Doenjang during Fermentation}

To examine the effect of the microflora, fermentation time, and doenjang matrix on aflatoxin reduction, doenjang samples were artificially contaminated with commercial aflatoxins B1, G1, B2, and G2. In addition, doenjang samples were inoculated with aflatoxin-producing A. flavus to examine their mycotoxin-producing behavior during the fermentation. Threemonth-old doenjang samples were used to carry out this experiment, as the samples at this stage contained trace amounts of mycotoxins, which disappeared eventually, thus providing a preliminary indication that they may contain some microorganisms that could effectively reduce the mycotoxins. All aflatoxin-spiked doenjang samples were fermented for 12 months at room temperature to monitor the changes in aflatoxin levels.

On the initial day, the control doenjang sample (not spiked with mycotoxins) showed a trace amount $(<0.50 \mu \mathrm{g} / \mathrm{kg})$ of aflatoxin, which eventually disappeared after 1 month of fermentation. On the initial day, commercial aflatoxin-spiked doenjang was recovered with $79.07 \pm 10.55 \mu \mathrm{g} / \mathrm{kg}$ aflatoxin B1, $84.54 \pm 14.40 \mu \mathrm{g} / \mathrm{kg}$ aflatoxin G1, 83.29 $\pm 4.56 \mu \mathrm{g} / \mathrm{kg}$ aflatoxin B2, and $81.92 \pm 7.09 \mu \mathrm{g} / \mathrm{kg}$ aflatoxin G2 (Figure 2b). After 12 months, aflatoxins B1 
and B2 were reduced to $5.86 \pm 1.84 \mu \mathrm{g} / \mathrm{kg}$ and $1.09 \pm 1.80 \mu \mathrm{g} / \mathrm{kg}$, respectively, in doenjang. A complete reduction of aflatoxins G1 and G2 was observed after 12 months of fermentation (Figure 2b). During 12 months, the total aflatoxin levels were reduced to $6.95 \pm 3.64 \mu \mathrm{g} / \mathrm{kg}$ from the $328.83 \pm 36.6 \mu \mathrm{g} / \mathrm{kg}$ detected at the beginning of fermentation (Figure 2c). These findings suggest a periodic reduction of aflatoxins during fermentation, which might be due to the presence of diverse microflora in doenjang that can degrade aflatoxins. Previously, the presence of aflatoxin-degrading microorganisms had been documented in various fermented foods [21,22], which supports our assumption that diverse microflora present in doenjang are the major contributors to the reduction of aflatoxins. Nevertheless, no study to date has demonstrated the involvement of microorganisms in the reduction of aflatoxins in doenjang. A detailed study confirming microorganism-mediated aflatoxin degradation is carried out in a later section.

(a)

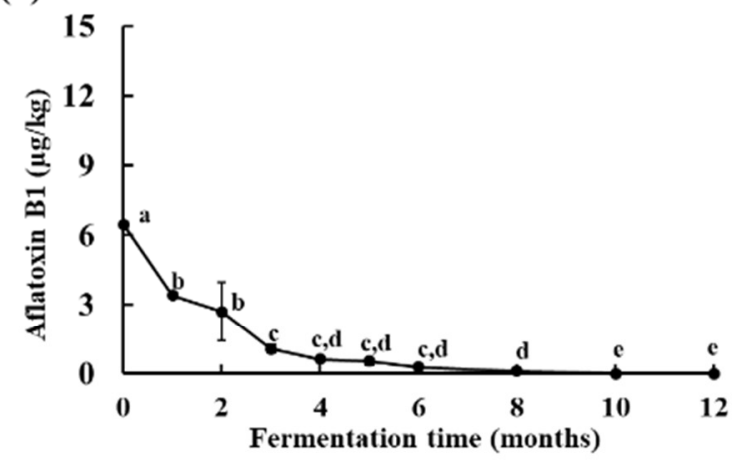

(b)

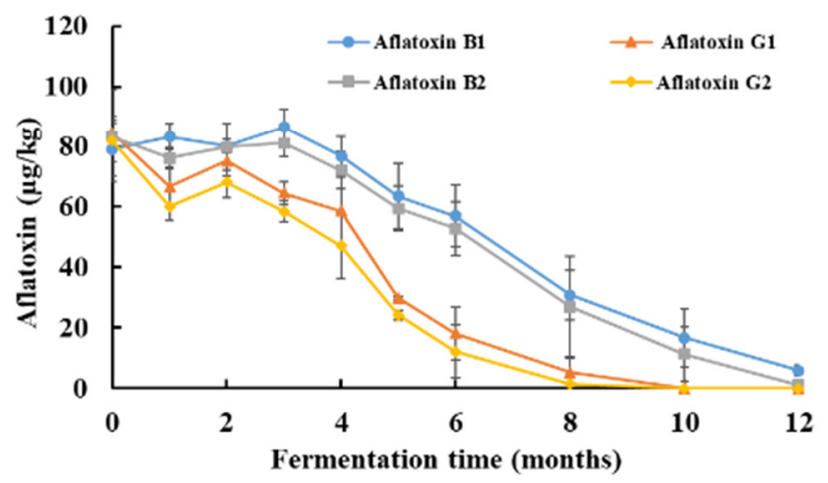

(c)

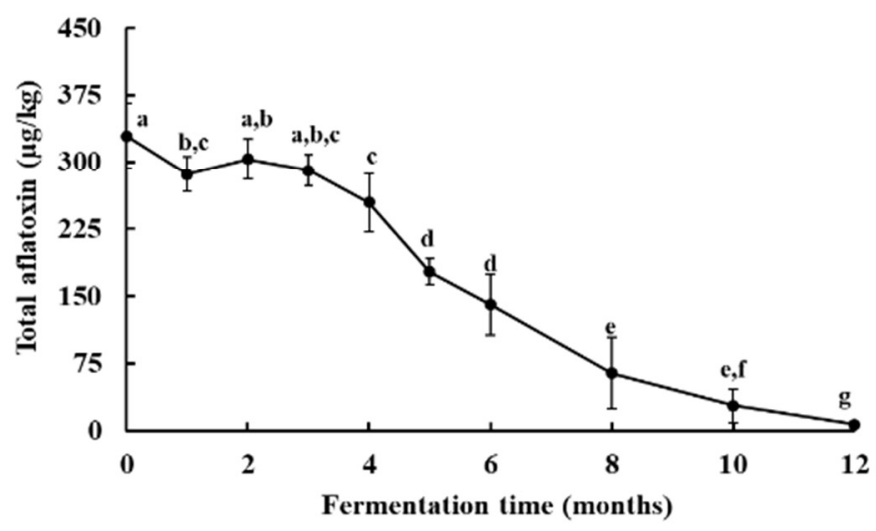

Figure 2. Analysis of aflatoxin in Aspergillus flavus-inoculated and aflatoxin-spiked ( $100 \mu \mathrm{g} / \mathrm{kg}$ each of aflatoxins B1, G1, B2, and G2) doenjang samples during 12 months of fermentation. (a) Quantification of aflatoxin B1 in Aspergillus flavus inoculated doenjang during 12 months of fermentation. (b) Timedependent quantification of aflatoxins B1, G1, B2, and G2 in aflatoxin-spiked doenjang samples. (c) Time-dependent quantification of total aflatoxin in aflatoxin-spiked doenjang samples. Each value represents the mean \pm standard deviation of three independent experiments. Different letters (a-g) represent a significant difference at $p<0.05$.

In the A. flavus inoculated samples, $6.45 \pm 0.05 \mu \mathrm{g} / \mathrm{kg}$ of aflatoxin B1 was detected on the first day, which was completely disappeared after 12 months of fermentation (Figure 2a). These results were surprising, as aflatoxin production was expected during the fermentation because doenjang samples were inoculated with aflatoxin-producing $A$. flavus. These results might be due to the high salt concentration of doenjang, which restricts the growth of $A$. flavus and, consequently, the production of aflatoxin. In addition, it might be possible that doenjang contains microorganisms that have an inhibitory effect on $A$. flavus. This is consistent with earlier reports demonstrating the $A$. flavus-inhibitory role of the microorganisms present 
in doenjang [23-25]. The findings indicated a non-conducive environment for A. flavus growth and aflatoxin production in doenjnag, and as a result, no production of aflatoxin was detected. Moreover, the $A$. flavus growth and aflatoxin production were also affected by the aerobic and anaerobic fermentation conditions [26]. Generally, the growth of $A$. flavus and aflatoxin production are negatively correlated with $\mathrm{CO}_{2}$ concentration. In a study, it was observed that $A$. flavus growth was effectively reduced at a $25 \% \mathrm{CO}_{2}$ level and aflatoxin production was significantly reduced at a $50 \% \mathrm{CO}_{2}$ level in high-moisture maize grains [27]. Similarly, a 59\% and an $88 \%$ reduction in A. flavus growth and a $47 \%$ and a $97 \%$ reduction in aflatoxin production in paddy by a $20 \%$ and an $80 \% \mathrm{CO}_{2}$ level were observed, respectively [28]. However, in the present study, doenjnag was kept in boxes where gases could pass freely, therefore ruling out the possibilities of $\mathrm{CO}_{2}$ accumulation and its negative impact on $A$. flavus growth and production of aflatoxin. Additionally, even on the surface, where plenty of oxygen was available, $A$. flavus growth and aflatoxin production were not observed, which confirmed that $\mathrm{CO}_{2}$ or $\mathrm{O}_{2}$ was not the limiting factor in the present study. Furthermore, A. flavus was not able to grow or produce aflatoxin at a high salt concentration $(>12 \%)$ in PDB medium where enough oxygen was available, also supporting the current findings. Therefore, these observations ruled out the possibility of the inhibition of $A$. flavus growth and aflatoxin production due to anaerobic conditions.

\subsection{Aflatoxin Production by A. flavus at Different Stages of Doenjang Preparation}

Aflatoxins were not detected in A. flavus-contaminated doenjang, indicating that $A$. flavus is not growing or is not producing aflatoxin in the doenjang environment. To evaluate and identify the stage of doenjang preparation that is most vulnerable to the A. flavus contamination and aflatoxin production, A. flavus was artificially inoculated at three different stages of doenjang preparation such as meju preparation, primary fermentation, and secondary fermentation stages. The analysis of the samples from different doenjang fermentation stages revealed that the meju preparation step was the most favorable stage for the growth of A. flavus and the production of aflatoxin. In the meju sample, an intense growth of $A$. flavus was detected (macroscopically). In contrast to this, no visible growth of $A$. flavus was detected in primary and secondary fermented samples. The meju samples inoculated with A. flavus showed $2678.32 \pm 111.39 \mu \mathrm{g} / \mathrm{kg}$ of aflatoxin B1 after 10 days of incubation (Figure $3 \mathrm{~b}$ ). In contrast, no aflatoxin production was detected in primary and secondary fermentation samples (Figure $3 a, c$ ). This suggests that the primary and secondary fermentation stages of the doenjang preparation do not favor the growth of $A$. flavus owing to the high salt concentrations. A similar study was carried out to observe $A$. flavus growth and aflatoxin production in peanuts, and it reported that $4 \% \mathrm{NaCl}$ inhibited aflatoxin production by A. flavus [29], which supports the current findings.

\subsection{Detection of Aflatoxins in Fungi Isolated from Doenjang}

Most of the doenjang samples inoculated with aflatoxin-producing A. flavus showed little or no presence of mycotoxins (Figure 2a), suggesting that the doenjang environment is unfavorable for their growth and/or aflatoxin production. In the control group, most of the samples were detected for trace amounts of aflatoxin, suggesting the presence of certain native aflatoxin-producing fungi. Therefore, different fungi were isolated from the doenjang samples and examined for aflatoxin production. Based on the colony morphology and culture characteristics, 14 different fungi were detected in different doenjang samples, which were further analyzed for aflatoxin production. Among the fourteen isolated strains, only three isolates (YURM3, YURM4, and YURM9) produced aflatoxins B1 and B2. Isolates YURM3, YURM4, and YURM9 produced $41.19 \mu \mathrm{g} / \mathrm{L}, 76.61 \mu \mathrm{g} / \mathrm{L}$, and $109.94 \mu \mathrm{g} / \mathrm{L}$ of aflatoxin B1 and $1.06 \mu \mathrm{g} / \mathrm{L}, 0.95 \mu \mathrm{g} / \mathrm{L}$, and $0.10 \mu \mathrm{g} / \mathrm{L}$ of aflatoxin B2. The remaining isolates did not produce any aflatoxin. The three aflatoxin-producing fungi were examined microscopically for tentative identification. Microscopic and culture characteristic examination revealed identical features of YURM3 and YURM9, which resembled the classical features of A. flavus. Therefore, both isolates were suspected to be $A$. flavus. However, the 
characteristics of YURM4 matched with the typical features of Aspergillus ruber; hence, it was tentatively identified as $A$. ruber. Further, the identification of these aflatoxin-producing strains was confirmed by molecular characterization based on internal transcribed spacer sequencing (Table 1 ).

(a)
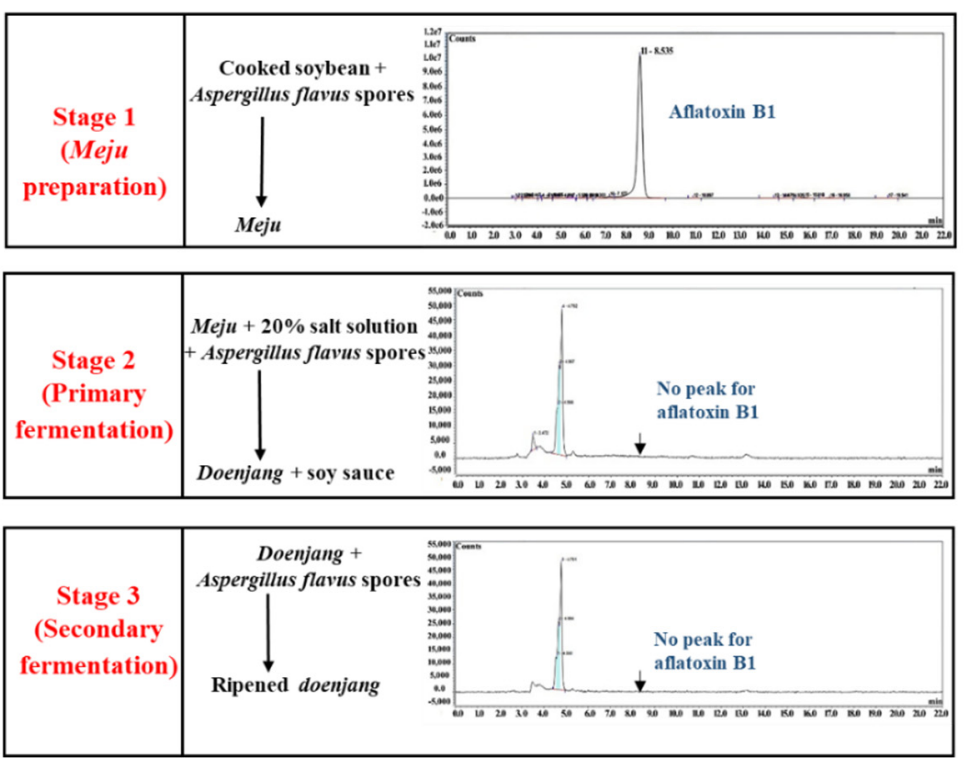

(b)

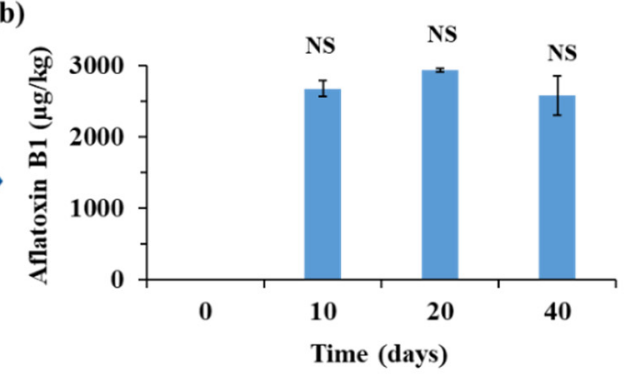

(c)

\begin{tabular}{|c|c|c|c|c|c|c|}
\hline Stage 1 & 0 day & 10 days & 20 days & 40 days & & \\
\hline $\begin{array}{c}\text { Alatoxin B1 } \\
(\mu \mathrm{gg} / \mathrm{kg})\end{array}$ & $0.00 \pm 0.00$ & $2678.32 \pm 111.39$ & $2935.68 \pm 20.95$ & $2580.64 \pm 273.52$ & & \\
\hline Stage 2 & 0 day & 15 days & 30 days & 45 days & 60 days & \\
\hline $\begin{array}{c}\text { Alfatoxin B1 } \\
(\mu \mathrm{g} / \mathrm{kg})\end{array}$ & $0.00 \pm 0.00$ & $0.00 \pm 0.00$ & $0.00 \pm 0.00$ & $0.00 \pm 0.00$ & $0.00 \pm 0.00$ & \\
\hline Stage 3 & 0 day & 1 month & 2 months & 3 months & 4 months & 6 months \\
\hline $\begin{array}{c}\text { Allatoxin B1 } \\
(\mu g / k g)\end{array}$ & $0.00 \pm 0.00$ & $0.00 \pm 0.00$ & $0.00 \pm 0.00$ & $0.00 \pm 0.00$ & $0.00 \pm 0.00$ & $0.00 \pm 0.00$ \\
\hline
\end{tabular}

Figure 3. Aflatoxin production by Aspergillus flavus at three different stages of the doenjang preparation. (a) Aflatoxin production at the meju stage (Stage 1), primary fermentation (Stage 2), and secondary fermentation (Stage 3). (b) Time-dependent aflatoxin B1 production at the meju stage. Values in the bar graph represent the mean \pm standard deviation of three independent experiments. (c) The combined results representing the time-dependent aflatoxin production by Aspergillus flavus at three different stages of doenjang preparation. NS: non-significant difference at $p<0.05$.

Table 1. Identification and general characteristics of aflatoxin-producing fungi isolated from doenjang and their mycotoxin production ability at different salt concentrations.

\begin{tabular}{|c|c|c|c|}
\hline Characteristics & Isolate YURM3 & Isolate YURM4 & Isolate YURM9 \\
\hline Surface view & & & \\
\hline Microscopic view & & & \\
\hline
\end{tabular}


Table 1. Cont.

\begin{tabular}{|c|c|c|c|c|}
\hline \multicolumn{2}{|c|}{ Characteristics } & Isolate YURM3 & Isolate YURM4 & Isolate YURM9 \\
\hline \multicolumn{2}{|c|}{$\begin{array}{c}\text { Identification } \\
\text { (ITS sequencing) }\end{array}$} & Aspergillus flavus & Aspergillus ruber & Aspergillus flavus \\
\hline \multirow{2}{*}{\multicolumn{2}{|c|}{$\begin{array}{c}\text { Growth temperature } \\
\text { Growth } \mathrm{pH}\end{array}$}} & $28^{\circ} \mathrm{C} \pm 2.0$ & $28^{\circ} \mathrm{C} \pm 2.0$ & $28^{\circ} \mathrm{C} \pm 2.0$ \\
\hline & & $5.6 \pm 0.2$ & $5.6 \pm 0.2$ & $5.6 \pm 0.2$ \\
\hline \multirow{2}{*}{ Growth p } & $0 \%$ & +++++ & +++++ & +++++ \\
\hline & $12 \%$ & +++ & ++ & +++ \\
\hline \multirow{5}{*}{$\begin{array}{l}\text { Growth at different } \\
\text { salt concentrations }\end{array}$} & $14 \%$ & No growth & No growth & No growth \\
\hline & $16 \%$ & No growth & No growth & No growth \\
\hline & $18 \%$ & No growth & No growth & No growth \\
\hline & $20 \%$ & No growth & No growth & No growth \\
\hline & $0 \%$ & 104.11 & 53.88 & 144.54 \\
\hline \multirow{5}{*}{$\begin{array}{c}\text { Toxin production at } \\
\text { different salt } \\
\text { concentrations } \\
(\mu \mathrm{g} / \mathrm{L})\end{array}$} & $12 \%$ & 79.27 & 0 & 88.22 \\
\hline & $14 \%$ & Not detected & Not detected & Not detected \\
\hline & $16 \%$ & Not detected & Not detected & Not detected \\
\hline & $18 \%$ & Not detected & Not detected & Not detected \\
\hline & $20 \%$ & Not detected & Not detected & Not detected \\
\hline
\end{tabular}

++ represents low growth, +++ represents moderate growth, +++++ represents high growth.

\subsection{Effect of Salt on the Growth of Aflatoxin-Producing Fungi}

As doenjang contains a high amount of salt ( 20\%) [30], the growth and aflatoxinproducing efficiency of YURM3, YURM4, and YURM9 and the standard aflatoxin-producing strain A. flavus were analyzed at different salt concentrations. The results revealed that the growth of YURM3, YURM4, and YURM9 beyond a 12\% salt concentration was not observed, suggesting that salt concentrations higher than $12 \%$ are an effective barrier to prevent the growth of these toxigenic isolates. Consistent with the growth, aflatoxin production was observed only up to a salt concentration of $12 \%$. Similarly, the medium without salt showed higher growth and aflatoxin production than the medium containing $12 \%$ salt (Table 1). Similar results were observed with the standard A. flavus strain, where growth and aflatoxin production were observed only up to a $12 \%$ salt concentration. These results suggest that the high amount of salt in doenjang prevents the growth of these toxigenic fungi, resulting in low or no aflatoxin production.

\subsection{Confirmation of Aflatoxin Degradation in Doenjang}

The control doenjang samples were stored in a refrigerator to prevent microbial activity. Additionally, a set of doenjang samples was autoclaved to eradicate the existing microorganisms and stored at room temperature. After 12 months, the stored samples were analyzed for the presence of residual aflatoxins (Figure 4). As a result, $75.18 \pm 0.73 \mu \mathrm{g} / \mathrm{kg}$ of aflatoxin B1, 71.65 $\pm 3.24 \mu \mathrm{g} / \mathrm{kg}$ of aflatoxin G1, $74.15 \pm 0.11 \mu \mathrm{g} / \mathrm{kg}$ of aflatoxin B2, and $74.67 \pm 4.26 \mu \mathrm{g} / \mathrm{kg}$ of aflatoxin G2 were recovered from the refrigerated doenjang samples (Figure S2a). The recovered amounts of aflatoxins were nearly the same as those recovered from doenjang samples collected on day 0 , indicating that there was no degradation during the storage at $4{ }^{\circ} \mathrm{C}$ (Figure S2b). From the autoclaved doenjang samples, $53.58 \pm 0.36 \mu \mathrm{g} / \mathrm{kg}$ of aflatoxin B1, $40.68 \pm 0.77 \mu \mathrm{g} / \mathrm{kg}$ of aflatoxin G1, $65.03 \pm 0.17 \mu \mathrm{g} / \mathrm{kg}$ of aflatoxin B2, and $45.26 \pm 0.95 \mu \mathrm{g} / \mathrm{kg}$ of aflatoxin G2 were recovered after 12 months of storage at room temperature (Figure S2a). The total aflatoxin recovered from the refrigerator-stored doenjang and the autoclaved doenjang stored at room temperature was 42- and 30-times higher, respectively, than that of the un-autoclaved doenjang stored at room temperature for 12 months (Figure S2b). The comparative result obtained from refrigerator-stored, room temperature-stored, autoclaved, and un-autoclaved doenjang samples implied a key involvement of native microorganisms in reducing aflatoxins during storage. As most of the microorganisms failed to grow at $4{ }^{\circ} \mathrm{C}$, no degradation of aflatoxins was noticed in refrigerator-stored doenjang. 


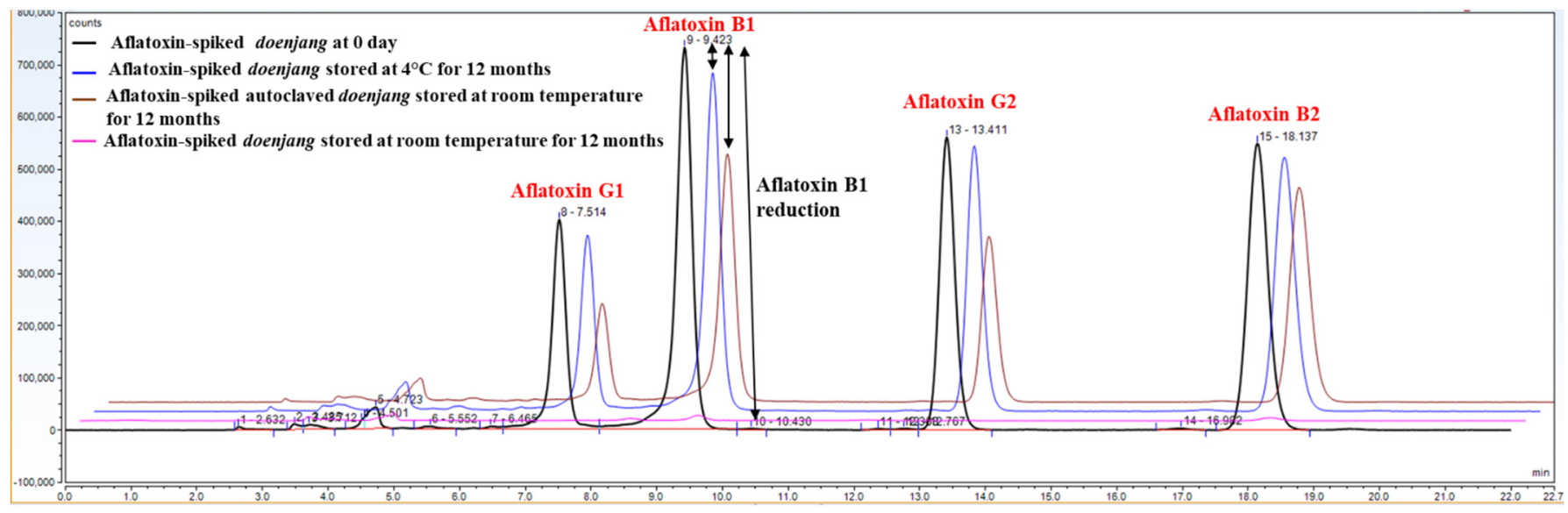

Figure 4. HPLC chromatograms representing aflatoxin levels in doenjang spiked with $100 \mu \mathrm{g} / \mathrm{kg}$ each of aflatoxins B1, G1, B2, and G2 on Day 0 and after 12 months of storage at $4{ }^{\circ} \mathrm{C}$ and room temperature $\left(25 \pm 2.5^{\circ} \mathrm{C}\right)$.

The autoclaved doenjang had a microorganism-free environment, but still showed some degree of aflatoxin degradation, suggesting the contribution of factors such as the doenjang matrix and physicochemical properties to degrade aflatoxin besides the sole involvement of microorganisms. The influence of microorganism's activity in both $4{ }^{\circ} \mathrm{C}$ and autoclaved doenjang was suppressed; however, the physical factors such as temperature contributed significantly to the degradation of aflatoxin, evident from the detected aflatoxin from un-autoclaved doenjang stored at room temperature. In autoclaved doenjang, temperature $\left(25 \pm 2.5^{\circ} \mathrm{C}\right)$ played a critical role to stimulate the physiochemical-induced aflatoxin degradation. The recovered aflatoxin from autoclaved and un-autoclaved doenjang stored at 12 months suggested that the majority of aflatoxin degradation was stimulated by microorganisms, though the physiochemical conditions also contributed significantly. Among the different chemical factors, the salt content of doenjang may be responsible for aflatoxin degradation, and this notion was supported by the in vitro study, where a significant amount of aflatoxin was degraded in the presence of a $20 \%$ salt solution during the storage of 60 days at room temperature (data not shown). These results collectively suggest that the microbial population is responsible for reducing the aflatoxin levels during fermentation. However, the physicochemical properties of doenjang also contribute to the degradation of aflatoxin to some degree.

These results are consistent with that demonstrated aflatoxin degradation in soybased products during fermentation primarily by microorganisms [31,32]. Similarly, Jeong et al. (2019) demonstrated aflatoxin reduction in doenjang during fermentation [9]. Lee et al. (2017) also observed aflatoxin reduction in doenjang and suggested the possibility of certain aflatoxin detoxifying microorganisms during fermentation [24]. Lee et al. (2017) isolated A. oryzae MAO 103 and MAO 104 from doenjang, which were able to degrade aflatoxins [24]. Consistent with this, Petchkongkaew et al. (2008) isolated 23 Bacillus species from soybean and fresh Thua-nao collected from the north of Thailand and observed that most of the strains could detoxify aflatoxin [33]. These results also support the present findings that fermented soybean-based products contain aflatoxin-degrading microorganisms. The results of the current findings indicate microorganisms as the major contributor to reducing aflatoxin in doenjang. However, other factors involved in aflatoxin degradation need to be explored in detail to decode the aflatoxin degradation mechanism.

\subsection{Aflatoxin Degradation by the Microbial Consortium Obtained from Doenjang}

The whole native microbial population was obtained from doenjang applied for aflatoxin degradation in nutrient broth. After five days of incubation, the residual aflatoxins were detected in the culture broth, CFS, and bacterial cell pellets. There was $316.44 \mu \mathrm{g} / \mathrm{L}$ of total residual aflatoxins detected in the nutrient broth inoculated with extracted mi- 
croorganisms against the initially spiked $400 \mu \mathrm{g} / \mathrm{L}$ of the total aflatoxins, representing a $20.89 \%$ reduction in the total aflatoxin levels (Figure 5). Specifically, $90.03 \mu \mathrm{g} / \mathrm{L}$ of residual aflatoxin B1 and $92.42 \mu \mathrm{g} / \mathrm{L}$ of residual aflatoxin B2 were detected in the whole culture broth of doenjang, which was initially spiked with $100 \mu \mathrm{g} / \mathrm{L}$ of each aflatoxin. In contrast, much smaller amounts of residual aflatoxin G1 $(64.15 \mu \mathrm{g} / \mathrm{L})$ and residual aflatoxin G2 $(69.84 \mu \mathrm{g} / \mathrm{L})$ were observed. These results indicate that aflatoxins G1 and G2 were more vulnerable to microbial degradation compared to aflatoxins B1 and B2. Furthermore, a considerable amount of total aflatoxins $(15.59 \mu \mathrm{g} / \mathrm{L})$ was detected in the bacterial pellet, suggesting that certain microbes present in the doenjang samples can adsorb aflatoxins as well. As shown in Figure 5, the adsorbed amount of total aflatoxin was very low, suggesting that microbial degradation is the major cause of the reduction in aflatoxin levels in doenjang samples. Doenjang is rich in diverse microflora such as aerobic bacteria, Lactobacillus, yeast, and fungi. Aerobic bacteria generally belong to the Bacillus group, the members of which are known to degrade aflatoxins $[33,34]$. The results correlated with our earlier findings demonstrating a time-dependent reduction of aflatoxins in doenjang samples and strongly support the notion that microorganisms in doenjang are the key contributors to reducing the aflatoxin levels.

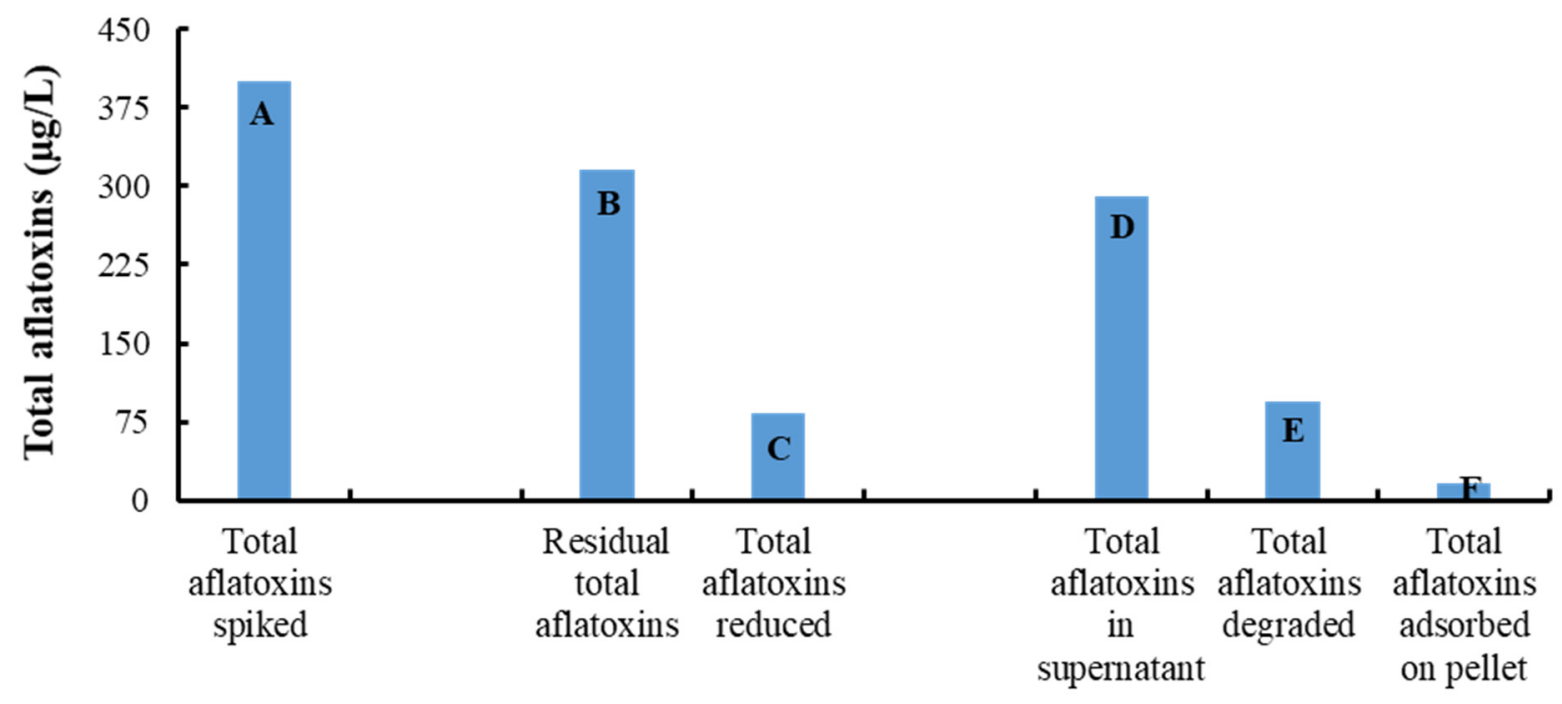

Figure 5. Degradation of aflatoxin $(100 \mu \mathrm{g} / \mathrm{kg}$ each of aflatoxins B1, G1, B2, and G2) by the microbial consortium obtained from doenjang. The bar column (A) represents the amount of total aflatoxins spiked. The bar columns (B) and (C) represent total residual aflatoxin (B) and the corresponding amount of the reduced aflatoxin (C), respectively, after 5 days of incubation. The bar columns (D), (E), and (F) represent total aflatoxin in the cell-free supernatant (D), degraded aflatoxin (E), and aflatoxin adsorbed by the microbial consortium obtained from doenjang $(\mathrm{F})$, respectively.

\subsection{Degradation of Aflatoxin by Microbial Isolates}

Nineteen bacteria were isolated from the doenjang samples. Based on microscopic examination and colony characteristics, eight distinct bacterial strains were selected for aflatoxin degradation analysis. The ability to degrade aflatoxins was observed in four isolates, YUN1, YUN3, YUN5, and YUY1, which displayed a 5.93-34.39\% degradation capability for aflatoxin B1, 78.97-96.67\% for aflatoxin G1, 9.94-38.80\% for aflatoxin B2, and $71.62-90.72 \%$ for aflatoxin G2 (Figure 6a). These four isolates were selected to examine the degradation of aflatoxins B1 and G1. The results showed that $5.74 \pm 3.14 \%, 19.27 \pm 4.24 \%$, $35.97 \pm 5.41 \%$, and $27.61 \pm 6.09 \%$ of aflatoxin B1 and $90.39 \pm 2.08 \%, 86.71 \pm 1.47 \%$, $89.74 \pm 1.37 \%$, and $84.83 \pm 1.36 \%$ of aflatoxin G1 were degraded by the bacterial isolates YUN1, YUN3, YUN5, and YUY1, respectively.

Similarly, 14 fungi were isolated from doenjang samples. Based on microscopic examination and colony characteristics, nine distinct fungal strains were selected for aflatoxin degradation analysis. The ability to degrade aflatoxins was observed in five isolates, 
YURM2, YURM5, YURM6, YURM7, and YURM8, which showed a 22.59-98.33\% degradation capability for aflatoxin B1, 88.76-100\% for aflatoxin G1, 29.57-95.91\% for aflatoxin B2, and $81.43-100 \%$ for aflatoxin G2 (Figure $6 \mathrm{~b}$ ). Of these five isolates, the three most effective isolates were selected to examine the degradation of aflatoxins B1 and G1. The results showed that $95.81 \pm 0.57 \%, 84.33 \pm 4.08 \%$, and $32.71 \pm 1.04 \%$ of aflatoxin B1 and $100 \pm 0.00 \%, 99.26 \pm 0.04 \%$, and $97.29 \pm 0.01 \%$ of aflatoxin G1 were degraded by fungal isolates YURM2, YURM6, and YURM8, respectively. These results indicated that some fungal species isolated from doenjang have a better capacity to degrade aflatoxin B1 compared to the bacterial isolates.

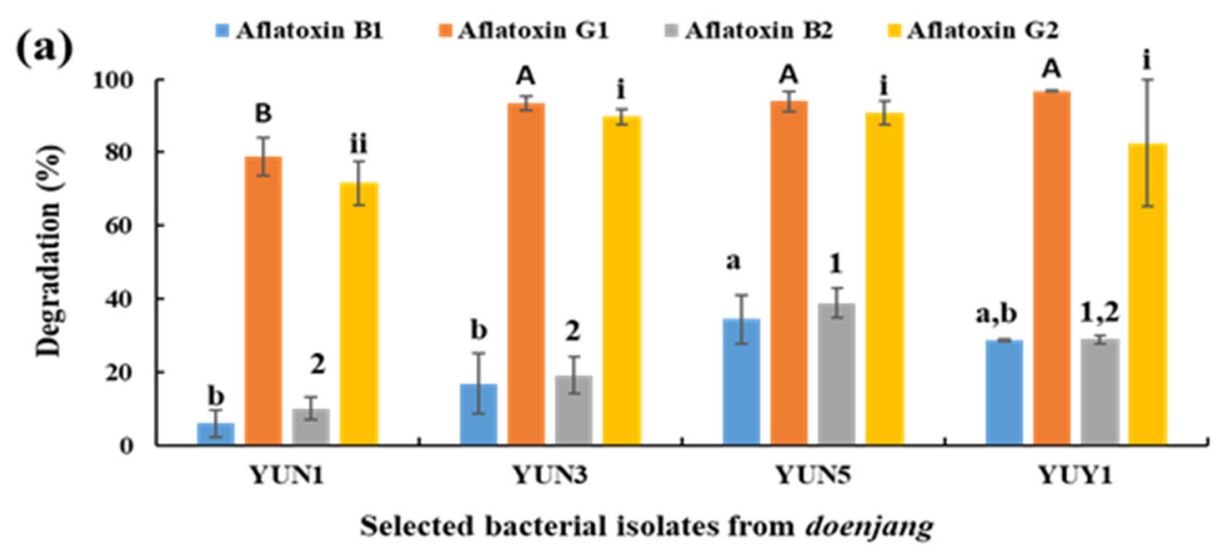

(b) : Aflatoxin B1 $=$ Aflatoxin G1 $=$ Aflatoxin B2 $=$ Aflatoxin G2

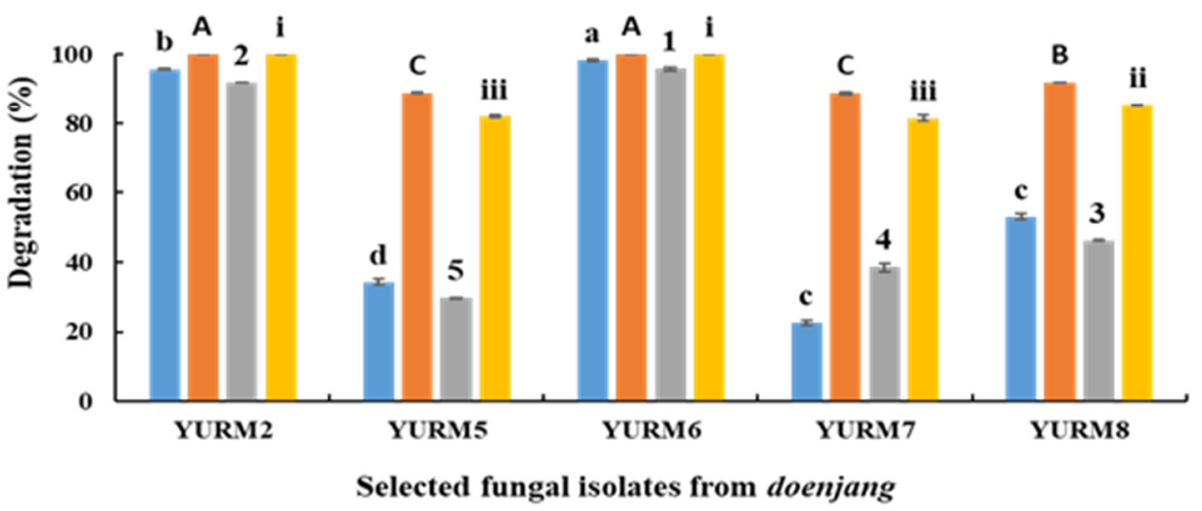

Figure 6. Degradation of aflatoxins by selected bacterial (a) and fungal (b) isolates from doenjang. Each value represents the mean \pm standard deviation of three independent experiments. Different lowercase letters $(a-d)$, uppercase letters $(A-C)$, numerical values (1-5), and roman letters (i-iii) represent a significant difference among the levels of aflatoxins B1, G1, B2, and G2 at $p<0.05$.

\subsection{Identification and Phylogenetic Analysis of the Isolated Microorganisms}

Based on molecular characterization and comparative phylogenetic analysis, the isolated bacterial strains YUN3, YUN5, and YUY1 showed the highest similarity with Bacillus albus. The isolated bacterial strain YUN1 was phylogenetically distinct from the other bacterial isolates (YUN3, YUN5, and YUY1) and identified as Bacillus velezensis (Figure 7a). The isolated fungi YURM2, YURM6, and YURM8 were found to be phylogenetically distinct and identified as the closest homologs of Aspergillus ochraceus, Aspergillus versicolor, and Cladosporium subcinereum, respectively (Figure $7 \mathrm{~b}$ ). Isolates YURM2 and YURM6 showed 100\% sequence similarity with A. ochraceus NRRL 398 and A. versicolor ATCC9757, respectively, whereas the isolate YURM8 displayed $98 \%$ sequence similarity with $C$. subcinereum UTHSC D1-13-257. The isolated Aspergillus species (A. ochraceus and A. versicolor) were found to be 
non-aflatoxin- and ochratoxin-A-producing fungi and were capable of degrading aflatoxins. These findings were consistent with an earlier report suggesting aflatoxin B1 degradation by atoxigenic A. flavus [35]. Similarly, the isolated A. ochraceus did not produce ochratoxin A, but was capable of degrading aflatoxin.

Several studies have previously reported the presence of similar microrganisms such as Bacillus sp. [22] and Aspergillus sp. [36] in fermented foods that were capable of degrading aflatoxins in different food and feed materials. Similarly, salt-tolerant aflatoxin-degrading microorganisms such as Candida versatilis and Tetragenococcus halophilus were isolated from soy sauce mash, which is a soybean-based product [37,38]. The presence of similar types of microorganisms in the prepared doenjang suggests that they are the major contributors to aflatoxin reduction. It is believed that the identified bacteria (YUN1, YUN3, YUN5, and YUY1) and fungi (YURM2, YURM6, and YURM8) from doenjnag are the key elements responsible for the reduction of aflatoxins during the fermentation. The isolated fungi YURM3 and YURM9 capable of producing aflatoxin were identified as the closest homologs of A. flavus, while the other aflatoxin-producing isolate YURM4 showed higher similarity with $A$. ruber (Figure $7 b$ ). Previously published reports suggested aflatoxin production by A. ruber [39]. In this current study, $A$. ruber responsible for aflatoxin B1 production was first detected in doenjang samples.

(a)

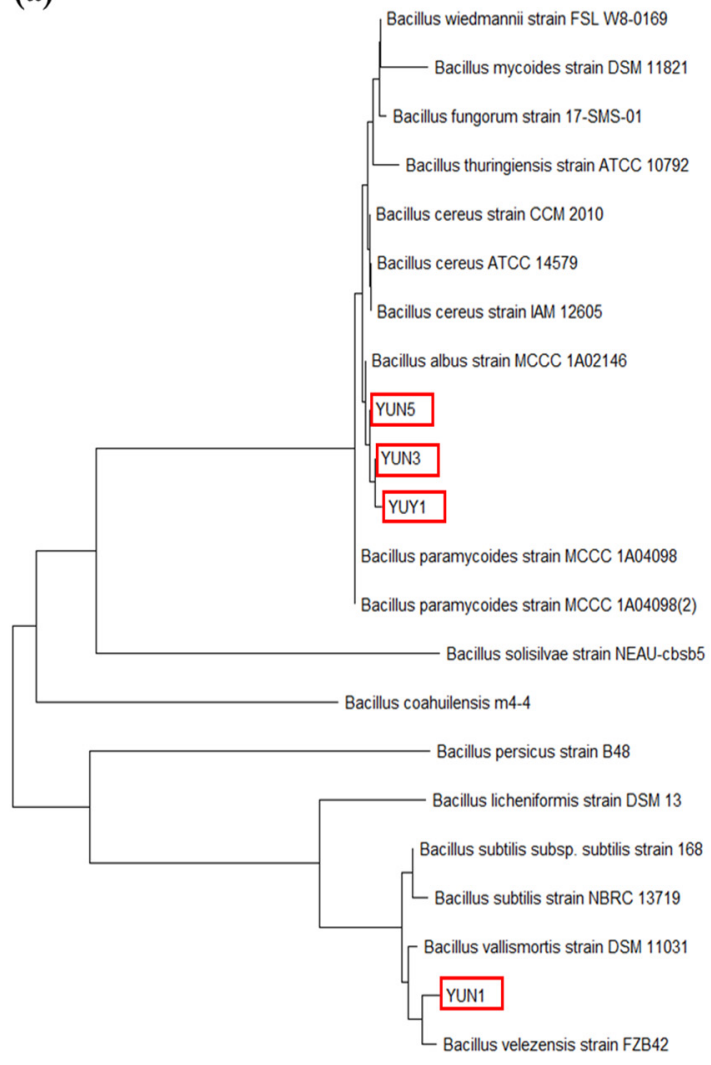

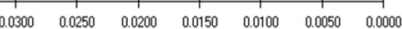

(b)

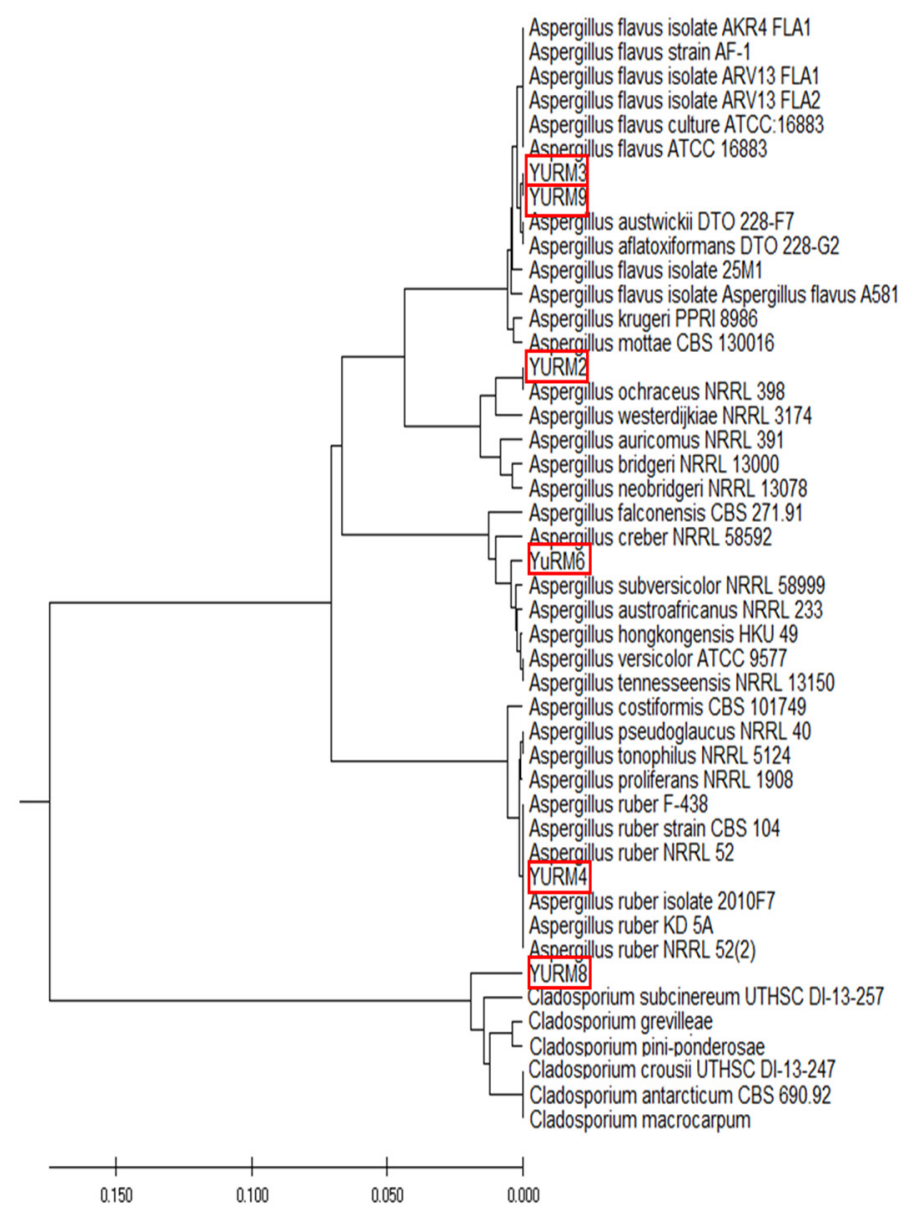

Figure 7. Comparative phylogenetic analysis of aflatoxin-degrading bacteria (a) and fungi (b) from doenjang samples. The phylogenetic tree was constructed using the MEGA6.0 software by employing the neighbor-joining method.

Doenjang is made of meju and salt and is naturally fermented by diverse microbial communities. In a recent study, four batches of doenjang and meju prepared from different manufacturers were analyzed for their microbial communities [40]. The microbial com- 
munities of meju varied from batch to batch. However, in some batches, the microbial communities in meju and doenjang were similar. Some microorganisms such as Aspergillus, Bacillus, and Enterococcus were present in all meju and doenjang samples [40], which supports the current findings that most of the isolated bacteria and fungi belong to the genera Bacillus and Aspergillus, respectively. These results are also supported by previous studies in which Pediococcus, Enterococcus, and Bacillus were reported as dominant bacteria in doenjang and ganjang $[4,41]$. Few other studies reported only Enterococcus and Bacillus as the dominant genera in meju and doenjang [6,42]. Aspergillus is a dominant fungus found in most soybean fermented foods and contributes to flavor and taste [43]. In this study, Cladosporium subcinereum was also isolated from doenjang and showed aflatoxin degradation ability. This is also supported by previous studies, which reported the isolation of Cladosporium sp. from теји [44].

\subsection{Toxicity Determination in Human Skin Fibroblast Cells}

The toxicity of aflatoxin and its degradation products in doenjang was examined using a cell viability assay. Aflatoxin and aflatoxin degradation products were extracted from doenjang samples collected on Day 0 and after 12 months of fermentation and examined for their effect on the viability of human skin fibroblasts. The extracted samples from Day 0 exhibited reduced human skin fibroblast cell viability $(49.94 \pm 4.96 \%)$ against the $100 \%$ cell viability of the control cells (without any treatment) (Figure 8 ). In contrast, cells exposed to the samples extracted from 12 months of fermentation displayed a significantly $(p<0.05)$ higher cell viability of $79.93 \pm 1.07 \%$, compared to that of the sample extracted on Day 0 (Figure 8). These results indicate that during the fermentation, aflatoxin was degraded by the diverse microorganisms present in doenjang into less toxic metabolites, and consequently, the toxicity was reduced. These results are supported by earlier studies suggesting the role of Pseudomonas putida, Bacillus subtilis, and Rhodococcus erythropolis in reducing aflatoxin toxicity towards HeLa cells [45-47].

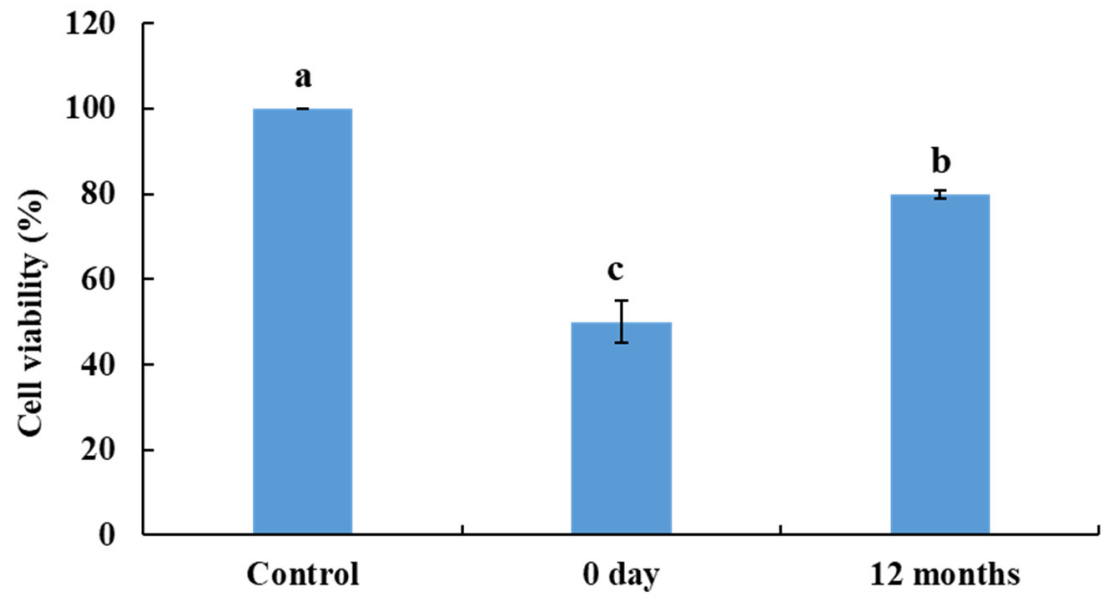

Figure 8. Viability of human skin fibroblasts in the presence of aflatoxin and its degradation products extracted on Day 0 and 12 months of fermentation from doenjang spiked with $100 \mu \mathrm{g} / \mathrm{kg}$ each of aflatoxins B1, G1, B2, and G2. Different letters (a-c) represent significant difference at $p<0.05$.

\section{Conclusions}

A time-dependent reduction in aflatoxin levels was observed in doenjang samples spiked with aflatoxins, suggesting that native microorganisms are the major contributor involved in the removal of these toxins. Moreover, the high salt concentration of doenjang, a unique physiochemical characteristic, prevents the growth of toxin-producing fungi and, thus, aflatoxin production. It was also observed that the aflatoxin contamination in doenjang arises mainly during the meju preparation stage; therefore, meju should be prepared under extremely hygienic conditions using good-quality grains. In conclusion, doenjang, which contains high levels of salt, is a complex food with diverse microorganisms 
that have aflatoxin degradation potential and are associated with the reduction of aflatoxin levels during fermentation. Therefore, storage of doenjang in the ambient environment for a prolonged time is advisable for the reduction of aflatoxins below the toxicity limit. Furthermore, the results of the study support the potential utilization of the microorganisms isolated from doenjang as starter cultures for the preparation of aflatoxin-free doenjang and as biological tools to clean up aflatoxins in various feed and food materials.

Supplementary Materials: The following are available online at https:/ /www.mdpi.com/article/ 10.3390/jof8020190/s1, Figure S1: Standard curve for (a) aflatoxin B1, (b) aflatoxin G1, (c) aflatoxin B2, and (d) aflatoxin G2; Figure S2: Quantification of (a) aflatoxin B1, G1, B2, and G2 and (b) total aflatoxins in doenjang samples at $4{ }^{\circ} \mathrm{C}$ and doenjang samples (autoclaved and un-autoclaved) at room temperature at 12 months of storage; Table S1: Limit of detection (LOD) and limit of quantification (LOQ) for aflatoxin B1, G1, G2, and B2; Table S2: Aflatoxin analysis in non-contaminated doenjang during 12 months fermentation.

Author Contributions: Conceptualization, V.K., A.B., J.S.L. and M.K.; methodology, V.K., A.B., J.S.L. and S.S.H.; software, V.K. and A.B.; validation, V.K., A.B. and J.S.L.; formal analysis, V.K., A.B., S.R. and J.S.L.; investigation, V.K., A.B. and J.S.L.; resources, M.K.; data curation, V.K., A.B., S.R. and J.S.L.; writing-original draft preparation, V.K. and A.B.; writing—-review and editing, V.K., A.B., H.S.C. and M.K.; visualization, H.S.C. and M.K.; supervision, M.K.; project administration, M.K.; funding acquisition, M.K. All authors have read and agreed to the published version of the manuscript.

Funding: This work was supported by the Ministry of Food and Drug Safety, Republic of Korea, in 2020 (Grant Number 20162MFDS007) and the National Research Foundation (NRF) grant funded by the Korean government (MSCT) (NRF-2021R1F1A1061945, NRF-2020R1A6A1A03044512).

Institutional Review Board Statement: Not applicable.

Informed Consent Statement: Not applicable.

Data Availability Statement: Data is contained within the article.

Conflicts of Interest: The authors declare no conflict of interest. The funders had no role in the design of the study; in the collection, analyses, or interpretation of the data; in the writing of the manuscript; nor in the decision to publish the results.

\section{References}

1. Wang, D.; Wang, L.J.; Zhu, F.X.; Zhu, J.Y.; Chen, X.D.; Zou, L.; Saito, M. In vitro and in vivo studies on the antioxidant activities of the aqueous extracts of Douchi (a traditional Chinese salt-fermented soybean food). Food Chem. 2008, 107, 1421-1428. [CrossRef]

2. Shukla, S.; Park, H.K.; Lee, J.S.; Kim, J.K.; Kim, M. Reduction of biogenic amines and aflatoxins in Doenjang samples fermented with various Meju as starter cultures. Food Control 2014, 42, 181-187. [CrossRef]

3. Kuligowski, M.; Pawlowska, K.; Jasinska-Kuligowska, I.; Nowak, J. Isoflavone composition, polyphenols content and antioxidative activity of soybean seeds during tempeh fermentation. CYTA J. Food 2017, 15, 27-33. [CrossRef]

4. Kim, T.W.; Lee, J.H.; Kim, S.E.; Park, M.H.; Chang, H.C.; Kim, H.Y. Analysis of microbial communities in doenjang, a Korean fermented soybean paste, using nested PCR-denaturing gradient gel electrophoresis. Int. J. Food Microbiol. 2009, 131, $265-271$. [CrossRef] [PubMed]

5. Xu, D.; Wang, P.; Zhang, X.; Zhang, J.; Sun, Y.; Gao, L.; Wang, W. High-throughput sequencing approach to characterize dynamic changes of the fungal and bacterial communities during the production of sufu, a traditional Chinese fermented soybean food. Food Microbiol. 2020, 86, 103340. [CrossRef]

6. Jung, J.Y.; Lee, S.H.; Jeon, C.O. Microbial community dynamics during fermentation of doenjang-meju, traditional Korean fermented soybean. Int. J. Food Microbiol. 2014, 185, 112-120. [CrossRef]

7. Hong, S.B.; Kim, D.H.; Samson, R.A. Aspergillus associated with Meju, a fermented soybean starting material for traditional soy sauce and soybean paste in Korea. Mycobiology 2015, 43, 218-224. [CrossRef]

8. Ting, W.E.; Chang, C.H.; Szonyi, B.; Gizachew, D. Growth and aflatoxin B1, B2, G1, and G2 production by Aspergillus flavus and Aspergillus parasiticus on ground flax seeds (Linum usitatissimum). J. Food Prot. 2020, 83, 975-983. [CrossRef]

9. Jeong, S.E.; Chung, S.H.; Hong, S.Y. Natural occurrence of aflatoxins and ochratoxin A in meju and soybean paste produced in South Korea. Appl. Biol. Chem. 2019, 62, 65. [CrossRef]

10. IARC Working Group on the Evaluation of Carcinogenic Risks to Humans and International Agency for Research on Cancer. Some traditional herbal medicines, some mycotoxins, naphthalene and styrene. IARC Monogr. Eval. Carcinog. Risks Hum. 2002, 82, 171-249. 
11. Tian, F.; Lee, S.Y.; Woo, S.Y.; Choi, H.Y.; Park, S.B.; Chun, H.S. Effect of plant-based compounds on the antifungal and antiaflatoxigenic efficiency of strobilurins against Aspergillus flavus. J. Hazard. Mater. 2021, 415, 125663. [CrossRef]

12. Shukla, S.; Lee, J.S.; Park, H.K.; Kim, J.K.; Kim, M. Effect of novel starter culture on reduction of biogenic amines, quality improvement, and sensory properties of doenjang, a traditional Korean soybean fermented sauce variety. J. Food Sci. 2015, 80, M1794-M1803. [CrossRef] [PubMed]

13. Tamura, K.; Stecher, G.; Peterson, D.; Filipski, A.; Kumar, S. MEGA6: Molecular evolutionary genetics analysis version 6.0. Mol. Biol. Evol. 2013, 30, 2725-2729. [CrossRef] [PubMed]

14. Bahuguna, A.; Khan, I.; Bajpai, V.K.; Kang, S.C. MTT assay to evaluate the cytotoxic potential of a drug. Bangladesh J. Pharmacol. 2017, 12, 115-118. [CrossRef]

15. Kim, M.; Kim, Y.S. Detection of foodborne pathogens and analysis of aflatoxin levels in home-made doenjang samples. Prev. Nutr. Food Sci. 2012, 17, 172-176. [CrossRef] [PubMed]

16. Na, H.S. Survey of mycotoxin contents of Korean traditional fermented foods in Jeollanam-do. J. Korean Soc. Food Sci. Nutr. 2016, 251. Available online: https://www.koreascience.or.kr/article/JAKO202018853212248.pdf (accessed on 13 December 2021).

17. Woo, S.Y.; Ryu, S.Y.; Tian, F.; Lee, S.Y.; Park, S.B.; Chun, H.S. Simultaneous determination of twenty mycotoxins in the Korean soybean paste doenjang by LC-MS/MS with immunoaffinity cleanup. Toxins 2019, 11, 594. [CrossRef]

18. Bae, S.I.; Kwak, B.Y.; Park, Y.K.; Kim, Y.H.; Shon, D.H. Survey of aflatoxin B1 in domestic doenjang and kochujang determined by enzyme linked-immunosorbent assay. J. Food Hyg. Saf. 2003, 18, 95-100.

19. Lee, G.I.; Lee, H.M.; Lee, C.H. Food safety issues in industrialization of traditional Korean foods. Food Control 2012, 24, 1-5. [CrossRef]

20. Park, K.Y. Aflatoxin: Factors affecting aflatoxin production. J. Korean Soc. Food Sci. Nutr. 1984, 13, 117-126.

21. Xu, D.; Wang, H.; Zhang, Y.; Yang, Z.; Sun, X. Inhibition of non-toxigenic Aspergillus niger FS10 isolated from Chinese fermented soybean on growth and aflatoxin B1 production by Aspergillus flavus. Food Control 2013, 32, 359-365. [CrossRef]

22. Watanakij, N.; Visessanguan, W.; Petchkongkaew, A. Aflatoxin B1-degrading activity from Bacillus subtilis BCC 42005 isolated from fermented cereal products. Food Addit. Contam. Part A 2020, 37, 1579-1589. [CrossRef] [PubMed]

23. Cho, K.M.; Math, R.K.; Hong, S.Y.; Islam, S.M.A.; Mandanna, D.K.; Cho, J.J.; Yun, M.G.; Kim, J.M.; Yun, H.D. Iturin produced by Bacillus pumilus HY1 from Korean soybean sauce (kanjang) inhibits growth of aflatoxin producing fungi. Food Control 2009, 20, 402-406. [CrossRef]

24. Lee, K.R.; Yang, S.M.; Cho, S.M.; Kim, M.; Hong, S.Y.; Chung, S.H. Aflatoxin B1 detoxification by Aspergillus oryzae from meju, a traditional Korean fermented soybean starter. J. Microbiol. Biotechnol. 2017, 27, 57-66. [CrossRef]

25. Lee, S.Y.; Woo, S.Y.; Ryu, S.Y.; Ok, H.E.; Chun, H.S. Aflatoxins in doenjang, a traditional Korean fermented soybean paste: A safety perspective. ACS Symp. Ser. 2019, 1303, 135-148.

26. Tai, B.; Chang, J.; Liu, Y.; Xing, F. Recent progress of the effect of environmental factors on Aspergillus flavus growth and aflatoxins production on foods. Food Qual. Saf. 2020, 4, 21-28. [CrossRef]

27. Giorni, P.; Battilani, P.; Pietri, A.; Magan, N. Effect of aw and $\mathrm{CO}_{2}$ level on Aspergillus flavus growth and aflatoxin production in high moisture maize post-harvest. Int. J. Food Microbiol. 2008, 122, 109-113. [CrossRef]

28. Mousa, W.; Ghazali, F.M.; Jinap, S.; Ghazali, H.M.; Radu, S.; Salama, A.E.R. Temperature, water activity and gas composition effects on the growth and aflatoxin production by Aspergillus flavus on paddy. J. Stored Prod. Res. 2016, 67, 49-55. [CrossRef]

29. Chitaree, K.; Kiatsompob, T.; Panchang, W.; Thanaboripat, D. Effect of salt concentrations on aflatoxin production in peanut by Aspergillus flavus. Agric. Nat. Resour. 1993, 27, 354-357.

30. Bahuguna, A.; Shukla, S.; Lee, J.S.; Bajpai, V.K.; Kim, S.Y.; Huh, Y.S.; Han, Y.K.; Kim, M. Garlic augments the functional and nutritional behavior of Doenjang, a traditional Korean fermented soybean paste. Sci. Rep. 2019, 9, 5436. [CrossRef]

31. Wei, R.D.; Chang, S.C.; Lee, S.S. High pressure liquid chromatographic determination of aflatoxins in soy sauce and fermented soybean paste. J. Assoc. Off. Anal. Chem. 1980, 63, 1269-1274. [CrossRef] [PubMed]

32. Park, K.Y.; Lee, K.B.; Bullerman, L.B. Aflatoxin production by Aspergillus parasiticus and its stability during the manufacture of Korean soy paste (doenjang) and soy sauce (kanjang) by traditional method. J. Food Prot. 1988, 51, 938-944. [CrossRef]

33. Petchkongkaew, A.; Taillandier, P.; Gasaluck, P.; Lebrihi, A. Isolation of Bacillus spp. from Thai fermented soybean (Thua-nao): Screening for aflatoxin B1 and ochratoxin A detoxification. J. Appl. Microbiol. 2008, 104, 1495-1502. [CrossRef] [PubMed]

34. Rao, K.R.; Vipin, A.V.; Hariprasad, P.; Appaiah, K.A.; Venkateswaran, G.J.F.C. Biological detoxification of aflatoxin B1 by Bacillus licheniformis CFR1. Food Control 2017, 71, 234-241.

35. Maxwell, L.A.; Callicott, K.A.; Bandyopadhyay, R.; Mehl, H.L.; Orbach, M.J.; Cotty, P.J. Degradation of aflatoxins B1 by atoxigenic Aspergillus flavus biocontrol agents. Plant Dis. 2021, 105, 2343-2350. [CrossRef] [PubMed]

36. Qiu, T.; Wang, H.; Yang, Y.; Yu, J.; Ji, J.; Sun, J.; Zhang, S.; Sun, X. Exploration of biodegradation mechanism by AFB1-degrading strain Aspergillus niger FS10 and its metabolic feedback. Food Control 2021, 121, 107609. [CrossRef]

37. Li, J.; Huang, J.; Jin, Y.; Wu, C.; Shen, D.; Zhang, S.; Zhou, R. Mechanism and kinetics of degrading aflatoxin B1 by salt tolerant Candida versatilis CGMCC 3790. J. Hazard. Mater. 2018, 359, 382-387. [CrossRef]

38. Li, J.; Huang, J.; Jin, Y.; Wu, C.; Shen, D.; Zhang, S.; Zhou, R. Aflatoxin B1 degradation by salt tolerant Tetragenococcus halophilus CGMCC 3792. Food Chem. Toxicol. 2018, 121, 430-436. [CrossRef]

39. Leitao, J.; Le Bars, J.; Bailly, J.R. Production of aflatoxin B 1 by Aspergillus ruber Thom and Church. Mycopathologia 1989, 108, 135-138. [CrossRef] 
40. Ryu, J.A.; Kim, E.; Yang, S.M.; Lee, S.; Yoon, S.R.; Jang, K.S.; Kim, H.Y. High-throughput sequencing of the microbial community associated with the physicochemical properties of meju (dried fermented soybean) and doenjang (traditional Korean fermented soybean paste). LWT-Food Sci. Technol. 2021, 146, 111473. [CrossRef]

41. Han, D.M.; Chun, B.H.; Feng, T.; Kim, H.M.; Jeon, C.O. Dynamics of microbial communities and metabolites in ganjang, a traditional Korean fermented soy sauce, during fermentation. Food Microbiol. 2020, 92, 103591. [CrossRef] [PubMed]

42. Jung, W.Y.; Jung, J.Y.; Lee, H.J.; Jeon, C.O. Functional characterization of bacterial communities responsible for fermentation of doenjang: A traditional Korean fermented soybean paste. Front. Microbiol. 2016, 7, 827. [CrossRef] [PubMed]

43. Huang, Z.R.; Guo, W.L.; Zhou, W.B.; Li, L.; Xu, J.X.; Hong, J.L.; Liu, H.P.; Zeng, F.; Bai, W.D.; Liu, B.; et al. Microbial communities and volatile metabolites in different traditional fermentation starters used for Hong Qu glutinous rice wine. Food Res. Int. 2019, 121, 593-603. [CrossRef] [PubMed]

44. Lee, L.; Heo, S.; Jeong, D.W. Fungal microbial community profiles of meju, solar salt, and doenjang using pyrosequencing. Microbiol. Biotechnol. Lett. 2019, 47, 354-358. [CrossRef]

45. Samuel, M.S.; Sivaramakrishna, A.; Mehta, A. Degradation and detoxification of aflatoxin B1 by Pseudomonas putida. Int. Biodeterior. Biodegrad. 2014, 86, 202-209. [CrossRef]

46. Eshelli, M.; Harvey, L.; Edrada-Ebel, R.; McNeil, B. Metabolomics of the bio-degradation process of aflatoxin B1 by actinomycetes at an initial $\mathrm{pH}$ of 6.0. Toxins 2015, 7, 439-456. [CrossRef]

47. Afsharmanesh, H.; Perez-Garcia, A.; Zeriouh, H.; Ahmadzadeh, M.; Romero, D. Aflatoxin degradation by Bacillus subtilis UTB1 is based on production of an oxidoreductase involved in bacilysin biosynthesis. Food Control 2018, 94, 48-55. [CrossRef] 